\title{
Efficacy and safety of chemotherapy after endoscopic double stenting for malignant duodenal and biliary obstructions in patients with advanced pancreatic cancer: a single-institution retrospective analysis
}

Kazuyuki Matsumoto $^{*}$ D, Hironari Kato, Shigeru Horiguchi, Koichiro Tsutsumi, Yosuke Saragai, Saimon Takada, Sho Mizukawa, Shinichiro Muro, Daisuke Uchida, Takeshi Tomoda and Hiroyuki Okada

\begin{abstract}
Background: Advanced pancreatic cancer is accompanied not only by bile duct obstruction, but also occasionally by duodenal obstruction. With new advances in chemotherapy and improvement in the management of stent dysfunction, the life expectancy of patients with pancreatic cancer has increased. This study aimed to evaluate the efficacy and safety of chemotherapy for advanced pancreatic cancer, as well as to analyze the prognostic factors, following endoscopic double stenting.
\end{abstract}

Methods: This retrospective study was conducted from January 1, 2007 to October 31, 2015 at an academic center. Fifty consecutive patients with pancreatic cancer who had undergone endoscopic double stenting, comprising duodenal and biliary stenting, were analyzed. We reviewed the patients records and analyzed the data of stent dysfunction rates after double stenting, reintervention for stent dysfunction, chemotherapy after double stenting, adverse events associated with chemotherapy after double stenting, survival times following double stenting, and overall survival times. The hospital's institutional review board for human research approved this study.

Results: The overall survival time and the survival time following double stenting were 10.9 months (IQR 6.018.4 months) and 2.4 months (IQR 1.4-5.2 months), respectively. After double stenting, duodenal stent dysfunction occurred in 6 patients (12\%), and biliary stent dysfunction occurred in 12 patients (24\%), respectively. All patients who experienced stent dysfunction underwent endoscopic reintervention, and all of the procedures were successful. Twenty-one (42\%) patients were treated with chemotherapy post double stenting; 9 patients received chemotherapy as a first-line treatment, 9 as a second-line treatment, and 3 as a third-line treatment. During chemotherapy, 8 (38\%) patients had grade 3-4 adverse events, which were manageable. Chemotherapy post double stenting $(\mathrm{OR}, 0.19 ; 95 \% \mathrm{Cl}$, $0.059-0.60 ; P=.0051)$, reintervention for biliary stent dysfunction $(\mathrm{OR}, 0.21 ; 95 \% \mathrm{Cl}, 0.081-0.50 ; P=.0002)$, and performance status $(<2)(\mathrm{OR}, 0.28 ; 95 \% \mathrm{Cl}, 0.098-0.71 ; P=.0064)$ were significant prognostic factors after double stenting.

Conclusions: Systemic chemotherapy was manageable, even in patients with double stenting. Chemotherapy after double stenting and appropriate reintervention for stent obstructions potentially prolonged the survival of patients with advance pancreatic cancer.

Keywords: Chemotherapy, Double stenting, Pancreatic cancer

\footnotetext{
* Correspondence: matsumotokazuyuki0227@yahoo.co.jp

Department of Gastroenterology and Hepatology, Okayama University

Graduate School of Medicine, Dentistry, and Pharmaceutical Science, 2-5-1

Shikata-cho, Okayama 700-8558, Japan
}

(c) The Author(s). 2018 Open Access This article is distributed under the terms of the Creative Commons Attribution 4.0 International License (http://creativecommons.org/licenses/by/4.0/), which permits unrestricted use, distribution, and 


\section{Background}

Pancreatic cancer is the fourth leading cause of cancer-related death in the United States [1] and fifth in Japan. Although surgical resection is the only curative treatment for this disease, more than $80 \%$ of patients with pancreatic cancer are diagnosed at unresectable stage. Advanced pancreatic cancer is accompanied not only by bile duct obstruction, but also sometimes by duodenal obstruction [2, 3]. These cause symptoms such as nausea, vomiting, anorexia, and weight loss, resulting in a marked decline in quality of life. Recently, the efficacy of treatment using biliary stenting (BS), which includes endoscopic retrograde cholangiopancreatography biliary drainage (ERCP-BD) and endoscopic ultrasound-guided (EUS)-BD, and duodenal stenting (DuS; also known as double stenting), has been described to improve the clinical symptoms of patients [4-9].

With the advent of new oncologic therapies and improvement in the management of adverse events of chemotherapy, the life expectancy of patients with pancreatic cancer has steadily increased [10-12]. In a recent study, patients who received chemotherapy after placement of duodenal stent for advanced cancer show better survival than the patients who did not receive chemotherapy [13-15]. Control of clinical symptoms associated with advanced cancer, such as gastric outlet obstruction (GOO) and obstructive jaundice, is required.

Systemic chemotherapy in patients who had undergone double stenting for advanced pancreatic cancer is difficult, because management of both bile duct and duodenal stents are required. Current studies showed that endoscopic double stenting, including reintervention for stent dysfunction, is technically feasible and clinically effective for advanced pancreatobiliary cancer $[5,9]$. However, chemotherapy in patients who had undergone double stenting has not been reported. Therefore, in this study, we aimed to evaluate the efficacy and safety of chemotherapy for advanced pancreatic cancer, as well as to analyze the prognostic factors, following double stenting.

\section{Methods}

\section{Patients}

Fifty consecutive patients with pancreatic cancer who had undergone endoscopic double stenting, comprising DuS and BS, from January 1, 2007 to October 31, 2015 at our institution, were retrospectively analyzed. The records of these patients were reviewed, and the following data were analyzed: patient characteristics, duodenal stenosis sites, timings of double stenting, selected BD methods, stent patency periods, technical and clinical success rates for reintervention, chemotherapy after double stenting, adverse events associated with chemotherapy after double stenting, time from initial diagnosis to double stenting, survival times following double stenting, and overall survival times. The hospital's institutional review board for human research approved this study.

The duodenal stenosis types were classified according to the location of the stenosis relative to the ampulla of Vater, as follows: type I: proximal to and no involvement of the ampulla of Vater; type II: affecting the second part of the duodenum and the ampulla of Vater; and type III: affecting the third part of the duodenum without ampulla of Vater involvement [5]. In simultaneous type II stenosis cases, if passage of the scope was possible, we deployed the biliary metal stent (MS) or plastic stent (PS) through ERCP-BD, followed by the DuS. If passage of the scope was impossible, we evaluated the duodenal bulb invasion of the tumor to determine whether EUS-choledochoduodenostomy (EUS-CDS) was possible. If possible, we performed EUS-CDS first, followed by the DuS. Otherwise, we selected EUS-hepaticogastrostomy (EUS-HGS) for biliary drainage. In cases of biliary stenosis after DuS for metachronous type II stenosis, we attempted a transpapillary approach through the MS mesh following insertion of the scope into the lumen of the duodenal stent. If the transpapillary approach failed, we performed EUS-BD. EUS-CDS was adopted for cases without duodenal bulb invasion, while EUS-HGS was adopted for duodenal bulb invasion.

The method of reintervention for ERCP-BDs was following, a duodenal scope was inserted through the duodenal stent. PS exchange involved placing a guidewire into the target branch before PS removal, then inserting a 7-10 Fr PS. When tumor ingrowth or overgrowth obstructed the MS, we inserted a 5-7 Fr PS into the lumen of the previously deployed MS. The methods of reintervention for EUS-CDS was following, a duodenal scope or a forward-viewing endoscope was used. PS exchange involved occluded stent removal. Then, a seeking guidewire was passed through the fistula and a new PS was placed. When the MS obstructed with sludge, a stone retrieval balloon was used and removed the sludge.

The stent patency periods for DuS and BS were measured from the day on which double stenting was undertaken to the day on which the stent became dysfunctional, the day the patient died, or the day of the last follow-up appointment. Stent dysfunction included stent obstruction, stent migration, and cholangitis. Obstructive jaundice recurrence, which was based on laboratory examinations and biliary dilation on computed tomography (CT) images, was considered to result from biliary stent obstruction. Symptom recurrence associated with gastroduodenal obstruction, including nausea, vomiting, and difficulties with oral intakes, and a grossly 
dilated stomach on CT images was considered to be caused by duodenal stent obstruction. Cholangitis was defined as elevations of liver enzyme level and the presence of typical symptoms, including fever. For reintervention, clinical success of biliary stent was defined as a decrease in bilirubin level to $<75 \%$ of the pre-drainage levels within 30 days. Clinical success of duodenal stent was based on oral intakes before and after stent placement using the Gastric Outlet Obstruction Scoring System (GOOSS) [16]. Overall survival time was defined as the period between pathological diagnosis and patient death or lost to follow-up.

The basic chemotherapy regimen after double stenting is as follows: gemcitabine (Gemzar, intravenous $1000 \mathrm{mg}$ / $\mathrm{m}^{2}$ on days 1,8 , and 15 on a 28-day cycle; Eli Lilly and Company, Indianapolis, IN, USA), S-1 (TS-1, 80-100 mg/ day per oral from days 1 to 14 on a 21-day cycle; Taiho Pharmaceutical Co., Ltd., Tokyo, Japan), GEM/S-1 (Gemzar, $1000 \mathrm{mg} / \mathrm{m}^{2}$ on days 1 and 8 ; TS- $1,80-100 \mathrm{mg} /$ day from days 1 to 14 on a 21-day cycle), irinotecan (Topotecin, intravenous $180 \mathrm{mg} / \mathrm{m}^{2}$ on a 14-day cycle; Daiichi-Sankyo Co., Ltd., Tokyo, Japan), and modified FOLFIRINOX [mFOLFIRINOX; oxaliplatin $85 \mathrm{mg} / \mathrm{m}^{2}$ (Elplat; Yakult Honsha Co., Ltd., Tokyo, Japan), irinotecan $150 \mathrm{mg} / \mathrm{m}^{2}$, leucovorin $400 \mathrm{mg} / \mathrm{m}^{2}$ (Isovorin injection; Pfizer Inc., New York, NY, USA), and continuous infusion of fluorouracil $2400 \mathrm{mg} / \mathrm{m}^{2}$ over $46 \mathrm{~h}$ (5-FU injection; Kyowa Hakko Kirin Co., Ltd., Tokyo, Japan), with routine subcutaneous infusion port on a 14-day cycle]. The toxicities were assessed using the National Cancer Institute Common Terminology Criteria for Adverse Events, version 4 (CTCAE v4). Chemotherapy was continued until disease progression, intolerable adverse events, or patient refusal.

\section{Statistical analysis}

Continuous variables were expressed as median and range or interquartile range (IQR) or mean \pm standard deviation (SD). Chi-square test was performed to analyze categorical variables. Student's t-test was used to compare continuous variables. The biliary stent patency periods were estimated using the Kaplan-Meier method, and they were compared using the log-rank test. Factors with $P$ values $<.05$ were considered survival factors after double stenting using the forward method, and they were analyzed in a multiple logistic regression model. Odds ratios (ORs) and 95\% confidence intervals (CIs) were calculated. Two-tailed $P$ values $<.05$ were considered statistically significant. All analyses were performed using JMP Pro 12 (SAS Institute, Cary, NC, USA).

\section{Results}

\section{Patient characteristics}

Table 1 summarizes patient characteristics. The median age of the patients was 65 years (range 41-86 years).
Table 1 Clinical characteristics and outcome of the patients who underwent double stenting

\begin{tabular}{|c|c|}
\hline Parameter & Number \\
\hline Age, median (range), years & $65(41-86)$ \\
\hline Sex, male, $n(\%)$ & $33(66)$ \\
\hline Distant metastasis at initical diagnosis, $n(\%)$ & $33(66)$ \\
\hline Time from initial diagnosis to double stenting (IQR), mo & $5.9(1.1-12.1)$ \\
\hline \multicolumn{2}{|l|}{ Timing of duodenal and biliary stenoses, $n(\%)$} \\
\hline Simultaneous & $21(42)$ \\
\hline Metachronous & $29(58)$ \\
\hline \multicolumn{2}{|l|}{ Type of duodenal stenosis, $n(\%)$} \\
\hline I & $20(40)$ \\
\hline$\|$ & $21(42)$ \\
\hline III & $9(18)$ \\
\hline \multicolumn{2}{|l|}{ GOOSS score, mean \pm SD } \\
\hline Before DuS & $0.9 \pm 0.8$ \\
\hline After DuS & $2.8 \pm 0.4$ \\
\hline \multicolumn{2}{|l|}{ Biliary drainage methods, $n$ (\%) } \\
\hline ERCP-BD & $35(70)$ \\
\hline EUS-CDS & $12(24)$ \\
\hline EUS-HGS & $3(6)$ \\
\hline \multicolumn{2}{|l|}{ Type of biliary stent } \\
\hline PS & $11(22)$ \\
\hline MS & $39(78)$ \\
\hline Chemotherapy post double stenting, $n$ (\%) & $21(42)$ \\
\hline \multicolumn{2}{|l|}{ Performance status at the double stenting, $n$ (\%) } \\
\hline $0-1$ & $28(56)$ \\
\hline $2-3$ & $22(44)$ \\
\hline Overall survital time (IQR), mo & $10.9(6.0-18.4)$ \\
\hline Survival time from double stenting (IQR), mo & $2.4(1.4-5.2)$ \\
\hline
\end{tabular}

IQR interquartile range, GOOSS gastric outlet obstruction scoring system

$S D$ standard deviation, DuS duodenal stenting

$E R C P-B D$ endoscopic retrograde cholangiopancreatography-guided biliary drainage

EUS-CDS endoscopic ultrasound-guided choledochoduodenostomy EUS-HGS endoscopic ultrasound-guided hepaticogastrostomy $P S$ plastic stent, MS metal stent

None of the patients had previous treatment. Thirty-three $(66 \%)$ patients had distant metastasis at the initial diagnosis. The median time from initial diagnosis to double stenting was 5.9 months (IQR 1.112.1 months). Double stenting was performed simultaneously in 21 (42\%) and metachronously in 29 (58\%) patients. Type I, II, and III duodenal stenosis had occurred in $20(40 \%), 21$ (42\%), and 9 (18\%) patients, respectively. GOOSS score increased from 0.9 [standard deviation (SD) 0.8] to 2.8 (SD 0.4) points following DuS $(P<.001)$. Selected BD methods for double stenting were ERCP-BD in 35 (70\%) patients, EUS-CDS in $12(24 \%)$ patients, and EUS-HGS in 3 (6\%) patients, respectively. 
The types of biliary stent used were PS in 11 (22\%) patients and MS in 39 (78\%) patients. Twenty-one (42\%) patients were treated with chemotherapy post double stenting. The performance status at double stenting was $0-1$ in 28 (56\%) patients and 2-3 in $22(44 \%)$ patients. The overall survival time and the survival time following double stenting were 10.9 months (IQR 6.0-18.4 months) and 2.4 months (IQR 1.4-5.2 months), respectively. During follow-up study, 47 (94\%) patients died.

\section{Stent dysfunction after double stenting}

The mean duodenal stent patency after double stenting was $106 \pm 136$ days (median not reached). During follow-up (median 73 days, IQR 44-131 days), duodenal stent dysfunction occurred in 6 patients (12\%). All patients who experienced stent dysfunction underwent endoscopic reintervention, and all of the procedures (2 patients for overgrowth, 2 patients for food impaction, 1 patient for stent migration) were successful. The GOOSS score increased from 0.6 (SD 0.5) to 2.2 (SD 0.8) points following reintervention $(P<.001)$.

The median biliary stent patency period after double stenting was 230 days (range 17-375 days). During follow-up (median 54 days, IQR 43-118 days), biliary stent dysfunction occurred in 12 patients (24\%). The median biliary stent patency period for MS and PS was 270 days (range 17-337) and 81 days (19-375), respectively $(P<.005)$. Of the 12 patients who experienced stent dysfunction (6 patients with MS, 6 patients with PS), 6 had undergone ERCP-BD and 6 had EUS-CDS. The median time of stent dysfunction after double stenting was 87 days (range 25-270 days). All patients who experienced stent dysfunction underwent endoscopic reintervention, and all of the procedures (7 patients for sludge, 3 patients for ingrowth, 1 patient for migration, 1 patient for kinking) were successful. However, one patient experienced clinical failure following ERCP-BD, thus the patient underwent an additional intervention using EUS-HGS. Therefore the clinical success rate was $92 \%(11 / 12)$.

\section{Post double stenting chemotherapy and adverse event}

Prior to double stenting, 26 (52\%) patients received chemotherapy and 10 (20\%) patients were treated with best supportive care (BSC). Both bile duct and duodenal obstruction developed simultaneously in the remaining $14(28 \%)$ patients at the initial diagnosis. After double stenting, 12 (46\%) out of 26 patients with chemotherapy could continue another chemotherapy, and 9 (64\%) out of 14 patients with simultaneous onset could start initial chemotherapy (Fig. 1). Results showed that 21 (42\%) patients received chemotherapy post double stenting; 9 patients received chemotherapy as a first-line treatment, 9 as a second-line treatment, and 3 as a third-line treatment. The regimens were GEM in 8 patients, $\mathrm{S}-1$ in 8 patients, CPT-11 in 2 patients, mFORFIRINOX in 2 patients, and GEM+S-1 in one patient. During chemotherapy, 8 (38\%) patients had grade 3-4 adverse events: neutropenia in 4, appetite loss in 2 , and diarrhea in 2 . However, these adverse events were manageable by dose reduction, drug holiday, or temporary drip. No fatal adverse events associated with chemotherapy were noted.

On the other hand, 29 (58\%) out of 50 patients who underwent double stenting received BSC because of

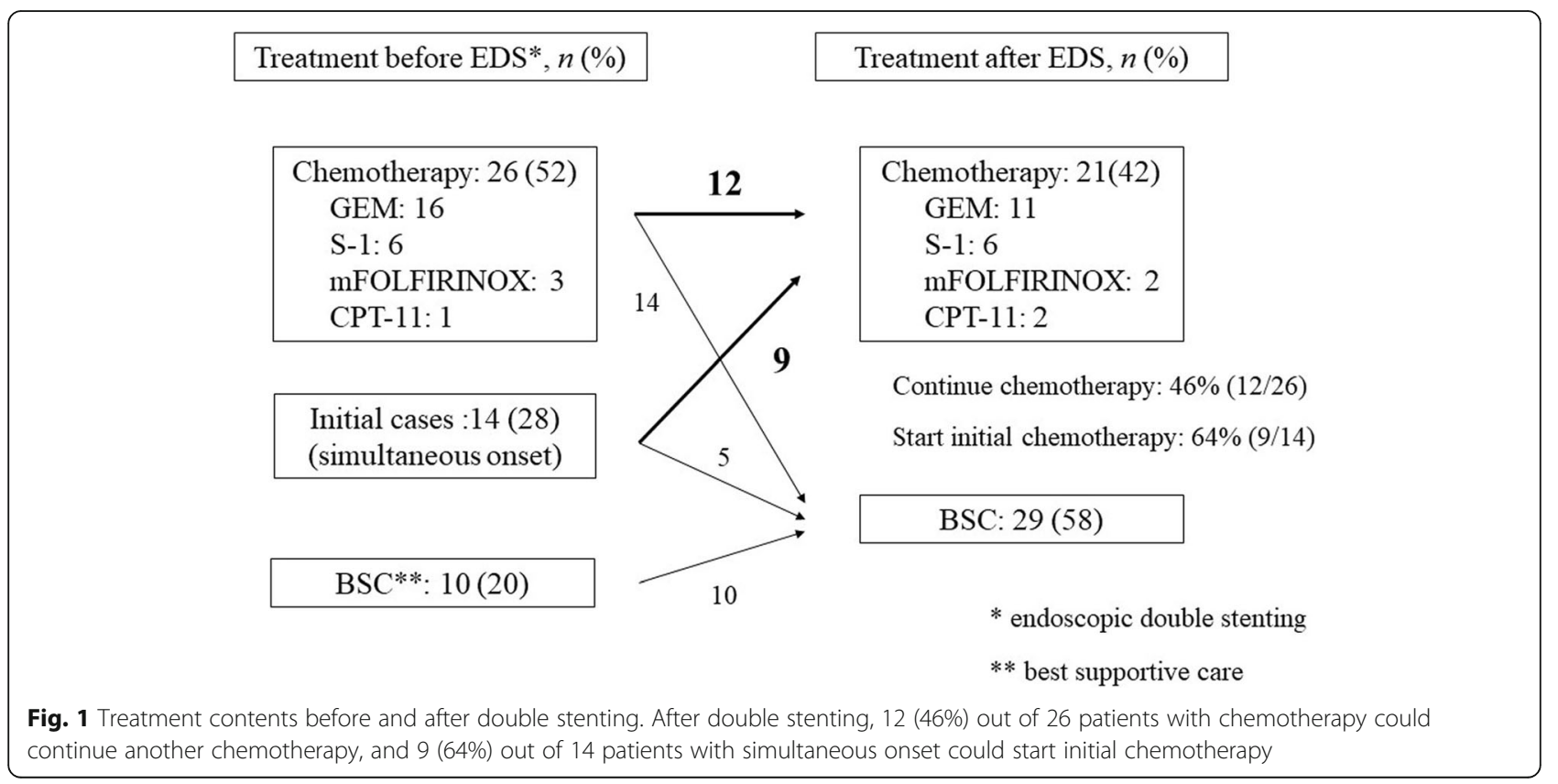


contraindications to systemic chemotherapy. These contraindications include poor general condition in 22, patient refusal in 5, and refractory to the standard treatment (GEM, TS-1, or mFOLFIRINOX) in 2 patients.

\section{Prognostic factors after double stenting}

The stent type, BD method, reintervention for duodenal stent dysfunction, reintervention for biliary stent dysfunction, chemotherapy post double stenting, and performance status were potential prognostic factors after double stenting $(P<.05)$ in the univariate analyses. Multiple logistic regression determined that reintervention for biliary stent dysfunction (OR, 0.21; 95\% CI, 0.081$0.50 ; P=.0002)$, chemotherapy post double stenting (OR, $0.19 ; 95 \% \mathrm{CI}, 0.059-0.60 ; P=.0051)$, and performance status $(<2)(\mathrm{OR}, 0.28 ; 95 \% \mathrm{CI}, 0.098-0.71 ; P=.0064)$ were significant prognostic factors after double stenting (Table 2).

\section{Comparison of survival times and prognostic factors}

The median survival time after double stenting was significantly longer in patients with reintervention for BS (189 days: IQR 115-325) than that in patients without reintervention (52 days: IQR $40-119) \quad(P=0.0025)$ (Fig. 2). It was also longer in patients with $\mathrm{PS}<2$ (155 days: IQR 77-325) than that in patients with $P S \geq 2$ (42 days: IQR 32-53) $(P=<.0001)$. Moreover, the median survival time was longer in patients with chemotherapy post double stenting (175 days: IQR 149-337) than that in patients without chemotherapy (46 days: IQR 34-60) $(P=<.0001)$ (Fig. 3). Considering the patients with PS $<2$, the median survival time after double stenting was significantly longer in patients with chemotherapy post double stenting (175 days: IQR 149-337) than that in patients without chemotherapy (77 days: IQR 53-87) $(P=0.0029)$ (Fig. 4).
Median survival time after double stenting for patients who had any chemotherapy $(n=35)$ and never had any chemotherapy $(n=15)$ was 101 days (IQR $51-224)$ and 43 days (IQR 34-87), respectively $(P=0.0029)$. Median survival time after double stenting for patients who had upfront double stenting, and then received frontline chemotherapy $(n=9)$ and double stenting during chemotherapy, and then continued second or third line chemotherapy $(n=12)$ was 325 days (IQR $149-375)$ and 158 days (IQR $89-337)$, respectively $(P=0.63)$ (Fig. 5$)$.

Median overall survival time for patients who had metastasis $(n=33)$ and without metastasis $(n=22)$ at the initial diagnosis was 264 days (IQR 197-489) and 410 days (IQR 223-791), respectively $(P=0.40)$. Median survival time after double stenting for patients who had metastasis and without metastasis at the initial diagnosis was 53 days (IQR 44-149) and 119 days (IQR 53-175), respectively $(P=0.46)$. Median overall survival time for patients who had simultaneous and metachronous double stenting was 264 days (IQR 123-410) and 367 days (IQR 223-647), respectively $(P=0.13)$. Median survival time after double stenting for patients who had simultaneous and metachronous was 149 days (IQR 49$255)$ and 53 days (IQR 40-101), respectively $(P=0.14)$.

\section{Discussion}

We retrospectively evaluated the efficacy and safety of post double stenting chemotherapy and analyzed the prognostic factors following double stenting. To our knowledge, this study is the first to evaluate chemotherapy in patients with double stenting for advanced pancreatic cancer.

Recent advances in systemic chemotherapies for pancreatic cancer enable not only first-line, but also second-line and/or third line chemotherapies, even in patients with advanced diseases [17, 18]. Several reports showed the efficacy and safety of systemic chemotherapies for patients

Table 2 Logistic regression analysis of survial time after double stenting

\begin{tabular}{|c|c|c|c|c|}
\hline \multirow[b]{2}{*}{ Variable } & \multicolumn{2}{|c|}{ Univariable analysis } & \multicolumn{2}{|c|}{ Multivariable analysis } \\
\hline & OR $(95 \% \mathrm{Cl})$ & $P$ value & OR $(95 \% \mathrm{Cl})$ & $P$ value \\
\hline Age $(\geq 65)$ & $0.79(0.43-1.42)$ & 0.43 & & \\
\hline Gender (M) & $0.77(0.40-1.53)$ & 0.45 & & \\
\hline Distant metastaisis at initial diagnosis (yes) & $1.26(0.69-2.42)$ & 0.46 & & \\
\hline Timing of double stenting (Simultaneous) & $0.64(0.34-1.17)$ & 0.15 & & \\
\hline Type of stent (PS) & $0.43(0.19-0.87)$ & 0.018 & $0.82(0.29-2.05)$ & 0.68 \\
\hline Biliary drainage method (EUS-BD) & $0.29(0.13-0.57)$ & 0.0002 & $0.45(0.16-1.13)$ & 0.093 \\
\hline Reintervention for DU stent dysfunction (yes) & $0.24(0.078-0.59)$ & 0.0012 & $0.42(0.098-1.54)$ & 0.19 \\
\hline Reintervention for BS dysfunction (yes) & $0.33(0.15-0.68)$ & 0.0018 & $0.21(0.081-0.50)$ & 0.0002 \\
\hline Chemotherapy post double stenting (yes) & $0.14(0.067-0.30)$ & $<.0001$ & $0.19(0.059-0.60)$ & 0.0051 \\
\hline Performance status $(<2)$ & $0.11(0.048-0.23)$ & $<.0001$ & $0.28(0.098-0.71)$ & 0.0064 \\
\hline
\end{tabular}

$O R$ odds ratio, $C l$ confidence interval, $P S$ plastic stent, EUS-BD endoscopic ultrasound-guided biliary drainage, $D U$ duodenal stent, $B S$ biliary stent 


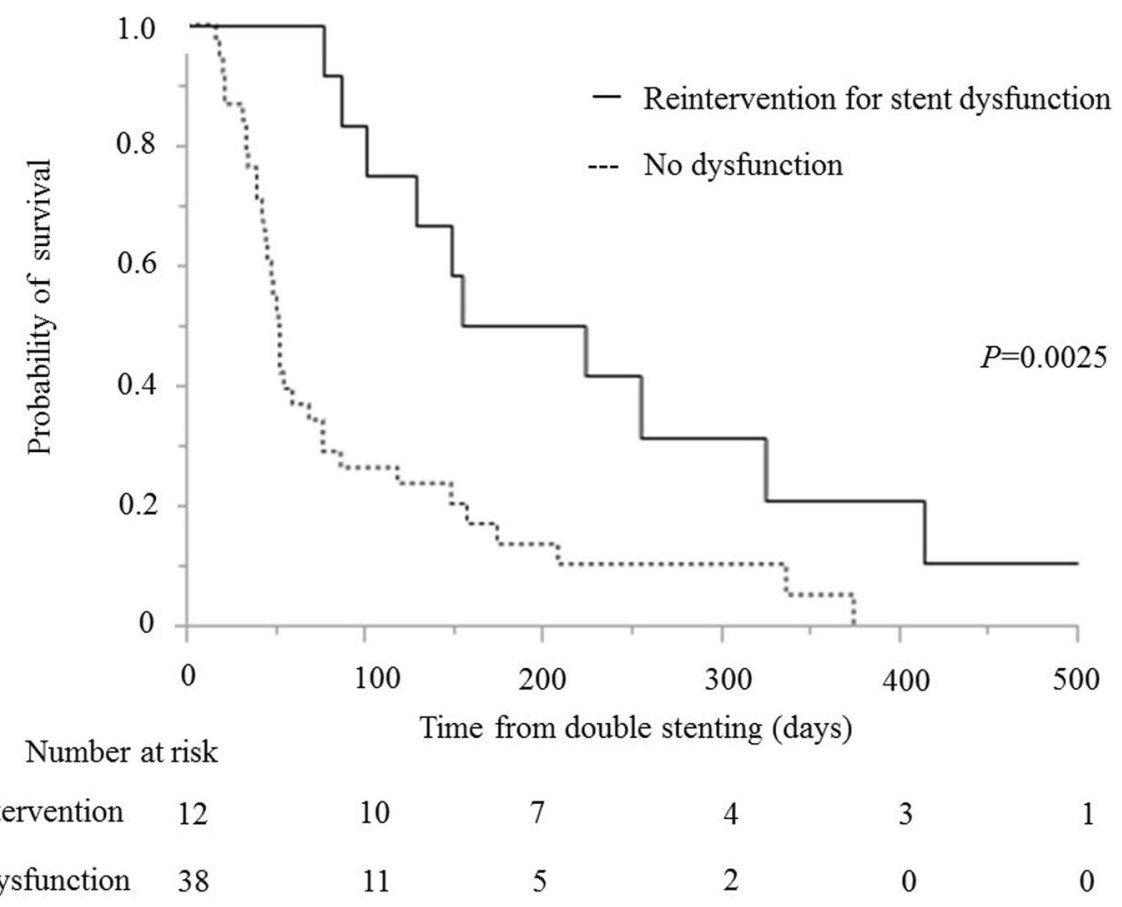

Fig. 2 Kaplan-Meier curve showing survival time following double stenting. Reintervention for biliary stent dysfunction versus no dysfunction (189 vs 52 days; $P=0.0025$ )

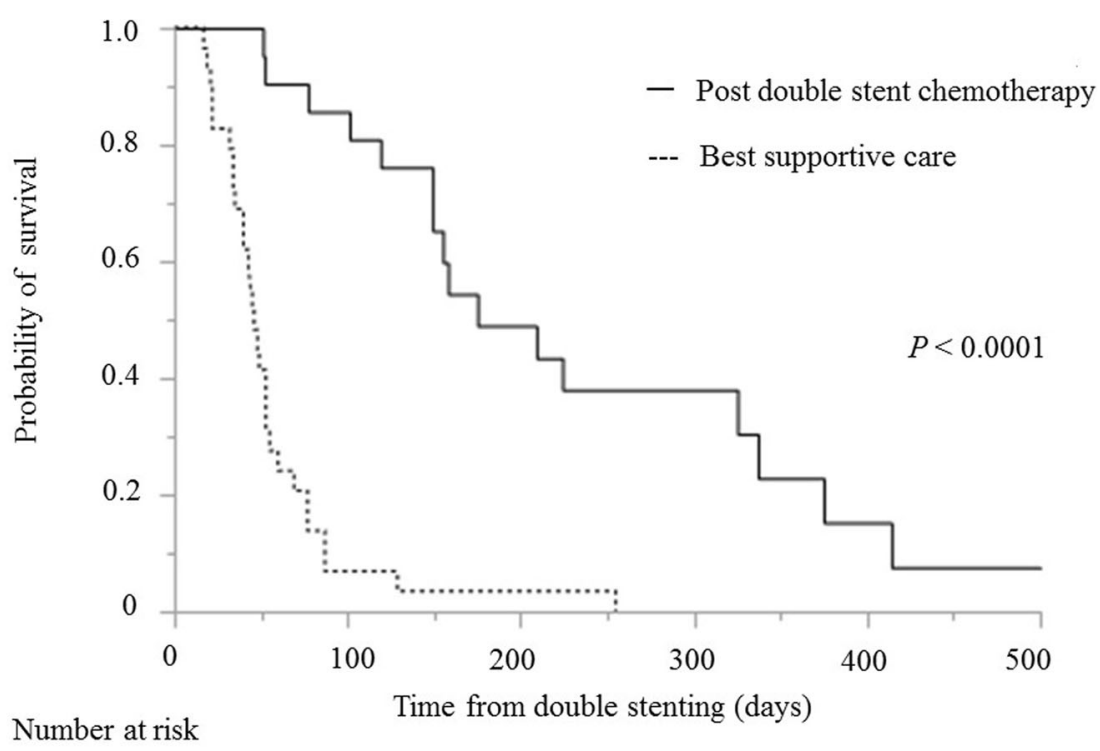

$\begin{array}{lcccccc}\text { Chemotherapy } & 21 & 19 & 10 & 7 & 3 & 1 \\ \text { BSC } & 29 & 4 & 1 & 0 & 0 & 0\end{array}$

Fig. 3 Kaplan-Meier curve showing survival time following double stenting. Chemotherapy versus best supportive care (no chemotherapy) (175 vs 46 days; $P=<.0001$ ) 


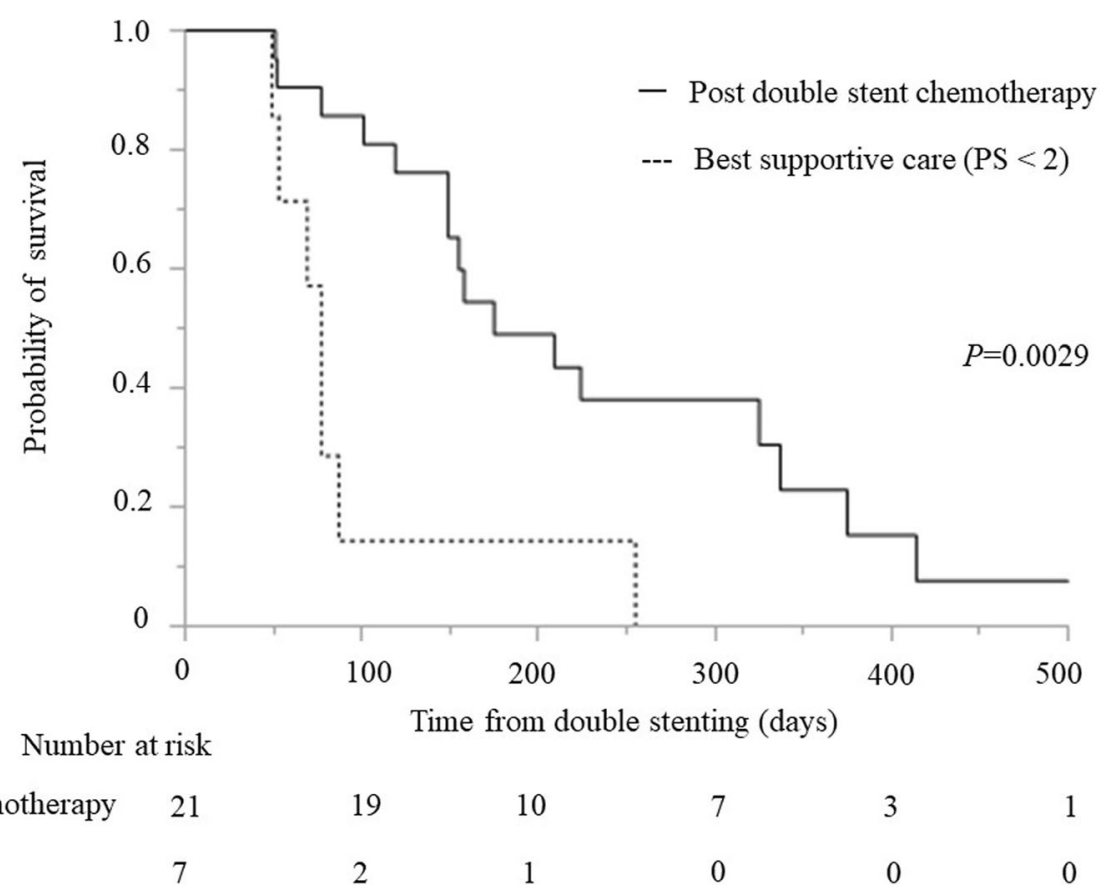

Fig. 4 Kaplan-Meier curve showing survival time following double stenting. Chemotherapy versus best supportive care with good performance status (0 or 1) (no chemotherapy) (175 vs 77 days; $P=0.0029$ )

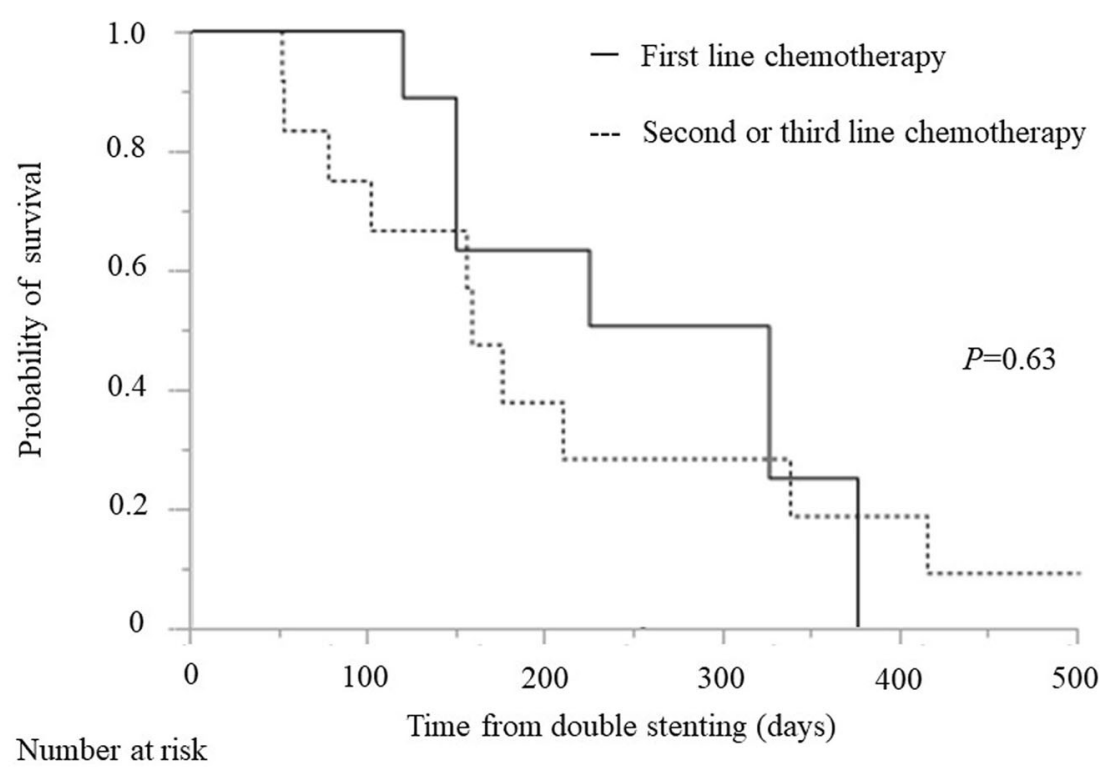

$\begin{array}{lllllll}\text { First line } & 9 & 9 & 7 & 4 & 0 & 0 \\ \text { Second/third line } & 12 & 10 & 5 & 4 & 3 & 1\end{array}$

Fig. 5 Kaplan-Meier curve showing survival time following double stenting. First line chemotherapy versus second or third line chemotherapy (325 vs 158 days; $P=0.63$ ) 
with advanced pancreatic cancer with GOO [13, 15]. Kobayashi et al. [15] showed that endoscopic DuS enables the initiation of systemic chemotherapy in more than $50 \%$ $(36 / 69)$ of patients. During treatment, 32\% (11/36) of patients developed grade 3-4 anemia, but no fetal adverse events associated with chemotherapy occurred. Survival analysis after post-stenting showed that introduction of chemotherapy was an independent factor of survival [HR: 1.85 (1.02-3.38), $P=0.045$ ]. Stephen et al. [13] reported that $50 \%(98 / 196)$ of patients with advanced pancreatic cancer could receive chemotherapy post duodenal stent placement. The median survival periods of the patients with post stent chemotherapy and without chemotherapy were 5.4 and 1.5 months $(P<.0001)$, respectively. In our study, $42 \%(21 / 50)$ of patients could receive chemotherapy even after double stenting. Moreover, 12 (46\%) out of 26 patients who received chemotherapy before double stenting could continue another chemotherapy, and 9 (64\%) out of 14 patients with simultaneous onset at the initial diagnosis could start initial chemotherapy. Median survival time after double stenting for patients who had upfront double stenting, and then received frontline chemotherapy $(n=9)$ and double stenting during chemotherapy, and then continued second or third line chemotherapy $(n=12)$ was 325 days (IQR $149-375)$ and 158 days (IQR $89-337)$, respectively $(P=0.63)$. There was no significant difference between front line chemotherapy and second or third line thermotherapy. Thus, we consider that continuing the chemotherapy even if second or third line had improved the survival time after double stenting. During chemotherapy, 8 (38\%) patients had grade $3-4$ adverse events, which were manageable. Of the 64 patients with advanced pancreatic cancer who had received chemotherapy (first line regimen; GEM 34, S-1 13, mFOLFIRINOX 11, GEM+S-1 6) without double stenting during 2012 October to 2015 October in our institution, $48 \%(31 / 64)$ patients had grade 3-4 adverse events (neutropenia in 22, leukopenia in 10 , thrombocytopemia in 2 , appetite loss in 3 , diarrhea in 2, fatigue in 1 , and rush in 1 : 10 patients had duplication). For first-line chemotherapy, the incidence of grade 3-4 adverse event was $44 \%$ (4/9) in patients with double stenting and $48 \%(31 / 64)$ in patients without double stenting, respectively $(P=0.82)$. Therefore, we considered that there was some tolerability of chemotherapy for the patients with double stenting. For survival analysis, the median survival time after double stenting was significantly longer in patients with chemotherapy post double stenting (175 days) than that in patients without chemotherapy (46 days) $(P=<.0001)$. Although the number of patients who received chemotherapy was small, administration of chemotherapy even after double stenting may contribute to prolonged prognosis.

Other prognostic factors after double stenting were reintervention for biliary stent dysfunction and performance status $(<2)$. The level of performance status is well known prognostic factor of chemotherapy for cancer [15]. In a recent report, the reintervention for biliary and duodenal stent dysfunction is technically feasible and clinically effective even after double stenting [5, 9]. In our study, the clinical success rate for biliary reintervention was $92 \%$ (11/12), and one patient who experienced clinical failure following ERCP-BD underwent an additional intervention using EUS-HGS. Out of 12 patients, 9 patients had received chemotherapy at the biliary stent obstruction. After reintervention, 8 patients could continue the chemotherapy. Moreover, in patients with stent dysfunction, the median time of stent dysfunction after double stenting was 87 days (range 25-270 days). The median survival time after double stenting in patients with no biliary stent dysfunction was 53 days (range 17-375) (median was not significant difference, $P=0.21$ ). Thus, if the endoscopic reintervention was not performed for biliary dysfunction, the survival time was not prolonged. Appropriate reintervention enabled to restart the chemotherapy, as the reintervention for biliary stent was the independent prognostic factor in this study. On the other hand, duodenal stent dysfunction occurred in only 6 patients. Although all patients who experienced stent dysfunction underwent endoscopic reintervention successfully, it did not show a prognostic value in this study.

This study has 2 limitations. First, it has a retrospective, single center design and comprises a small number of patients who received chemotherapy. Second, the patients did not receive the same resume and the line of chemotherapy after double stenting; various types of MS (covered or uncovered type) or PS were used. Thus, the survival period and stent dysfunction of both the duodenal and biliary stents were difficult to evaluate. These limitations are biased against the prognostic factors.

\section{Conclusions}

In conclusion, systemic chemotherapy was manageable, even in patients with double stenting. The chemotherapy after double stenting and appropriate reintervention for stent obstructions potentially prolonged the survival of patients with advanced pancreatic cancer.

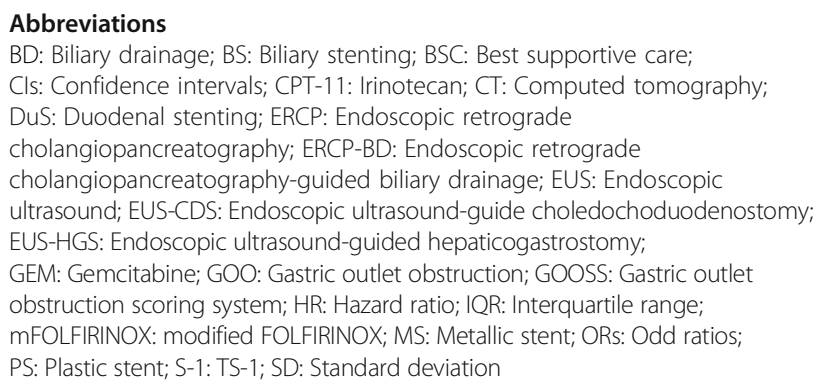

Acknowledgements

None 


\section{Funding}

None

\section{Availability of data and materials}

The datasets used and/or analyzed during the current study are available from the corresponding author on reasonable request.

\section{Authors' contributions}

$\mathrm{KM}$ and $\mathrm{HK}$, conception and design of the research and writing the paper; SH, SM and KT analysis and interpretation of data; YS, ST, SIM, DU, and TT, critical revision of the article for important intellectual content; and $\mathrm{HO}$, final approval of the article. All authors read and approved the final manuscript.

\section{Ethics approval and consent to participate}

This retrospective study was approved by the Okayama University Graduate School of Medicine, Dentistry and Pharmaceutical Sciences and Okayama University Hospital, Ethics Committee review board for human research (approval no.1601-503). This study obtained informed consent to participate by disclose information about this study on our institution HP (opt -out methods). All of the participants provided written informed consent of treatment (endoscopic procedure, chemotherapy).

\section{Consent for publication}

Not applicable

\section{Competing interests}

The authors declare that they have no competing interests.

\section{Publisher's Note}

Springer Nature remains neutral with regard to jurisdictional claims in published maps and institutional affiliations.

Received: 30 November 2017 Accepted: 16 October 2018

Published online: 26 October 2018

\section{References}

1. Seigel R, Naishadham D, Jemal A. Cancer statistics. CA Cancer J Clin. 2012; 62:10-29.

2. House MG, Choti MA. Palliative therapy for pancreatic/biliary cancer. Surg Clin North Am. 2005:85:359-71.

3. Singh SM, Longmire WP Jr, Reber HA. Surgical palliation for pancreatic cancer. The UCLA experience. Ann Surg. 1990;212:132-9.

4. Maire $F$, Hammel P, Ponsot $P$, et al. Long-term outcome of biliary and duodenal stents in palliative treatment of patients with unresectable adenocarcinoma of the head of pancreas. Am J Gastroenterol. 2006;101: $735-42$

5. Mutignani M, Tringali A, Shah G, et al. Combined endoscopic stent insertion in malignant biliary and duodenal obstruction. Endoscopy. 2007;39:440-7.

6. Iwamuro M, Kawamoto H, Harada R, et al. Combined duodenal stent placement and endoscopic ultrasonography-guided biliary drainage for malignant duodenal obstruction with biliary stricture. Dig Endosc. 2012;22: 236-40.

7. Kaw M, Singh S, Gagneja H. Clinical outcome of simultaneous selfexpandable metal stents for palliation of malignant biliary and duodenal obstruction. Surg Endosc. 2003;17:457-61.

8. Itoi T, Itokawa F, Sofuni A, et al. Endoscopic ultrasound-guided double stenting for biliary and duodenal obstruction. Endosc Ultrasound. 2012;1(1): $36-40$.

9. Matsumoto $\mathrm{K}$, Kato $\mathrm{H}$, Tsutsumi $\mathrm{K}$, et al. Long-term outcomes and risk factors of biliary stent dysfunction after endoscopic double stenting for malignant biliary and duodenal obstructions. Dig Endosc. 2017;29:617-25.

10. Von Hoff DD, Ervin T, Arena FP, et al. Increased survival in pancreatic cancer with nab-paclitaxel plus gemcitabine. N Engl J Med. 2013;369:1691-703.

11. Conroy T, Desseigne F, Ychou M, et al. FOLFINIROX versus gemcitabine for metastatic pancreatic cancer. N Engl J Med. 2011;364:1817-25.

12. Ghorani E, Wong HH, Hewitt C, et al. Safety and efficacy of modified FOLFIRINOX for advanced pancreatic adenocarcinoma: a UK single-Centre experience. Oncology. 2015;89:281-7.

13. Oh SY, Edwards A, Mandeison M, et al. Survival and clinical outcome after endoscopic duodenal stent placement for malignant gastric outlet obstruction: comparison of pancreatic cancer and nonpancreatic cancer. Gastrointest Endosc. 2015:82:460-468.e2.

14. Shah A, Fehmi A, Savides TJ, et al. Increased rates of duodenal obstruction in pancreatic cancer patients receiving modern medical management. Dig Dis Sci. 2014:59:2294-8.

15. Kobayashi S, Ueno M, Kameda R, et al. Duodenal stenting followed by systemic chemotherapy for patients with pancreatic cancer and gastric outlet obstruction. Pancreatology. 2016;16:1085-91.

16. Adler DG, Baron TH. Endoscopic palliation of malignant gastric outlet obstruction using self-expanding metal stents: experience in 36 patients. Am J Gastroenterol. 2002;97:72-8.

17. Portal A, Pernot $S$, Tougeron $D$, et al. Nab-paclitaxel plus gemcitabine for metastatic pancreatic adenocarcinoma after folfirinox failure: an AGEO prospective multicenter cohort. Br J Cancer. 2015;113:989-95.

18. Oettle H, Riess H, Stieler JM, et al. Second-line oxaliplatin, folinic acid, and fluorouracil versus folinic acid and fluorouracil alone of gemcitabinerefractory pancreatic cancer: outcomes from the CONKO-003 trial. J Clin Oncol. 2014;32:2423-9.

\section{Ready to submit your research? Choose BMC and benefit from:}

- fast, convenient online submission

- thorough peer review by experienced researchers in your field

- rapid publication on acceptance

- support for research data, including large and complex data types

- gold Open Access which fosters wider collaboration and increased citations

- maximum visibility for your research: over $100 \mathrm{M}$ website views per year

At BMC, research is always in progress.

Learn more biomedcentral.com/submissions 